\title{
Identification of Polyamide 6 and Polyamide 66 Oligomers Using Ion Mobility Time-of-flight Mass Spectrometry and Risk Assessment Study of Their Migration from Kitchenware to Foodstuff
}

\author{
Xuechao Song, Elena Canellas, Cristina Nerin \\ GUIA Group, Department of Analytical Chemistry, I3A, \\ Universidad de Zaragoza, Mariano Esquillor s/n, 50018, Zaragoza, Spain. \\ Tel.+34 976761873, e-mail: cnerin@unizar.es
}

\section{Summary}

Ion mobility time-of-flight mass spectrometry has been used for the identification the PA 6 and PA 66 oligomers through their accurate $\mathrm{m} / \mathrm{z}$, CCS values and fragmentation pattern. An extraction method for the oligomers from sunflower oil, cooked beans, soup and whole milk has been developed with recoveries ranging from 87 to $102 \%$.

\section{Results}

\section{Identification of migrants}

In order to identify the compounds migrating from the kitchenware to the food simulants the technique UPLC-IMS/QTOF was selected. This technique provides not only mass accuracy and molecular fragmentation that are parameters needed for molecular elucidation; it also provides ion mobility separation. Each compound analyzed has a collision cross section (CCS) value that will be related to its chemical structure and three-dimensional conformation. Table 1 shows the compounds identified, retention time, $\mathrm{m} / \mathrm{z}$ detected by UPLCIMS-Q-TOF, theoretical $\mathrm{m} / \mathrm{z}$, elemental composition and CCS value obtained for each one. Figure 1 shows the low and high energy spectrum for PA 6 tetramer

\section{Migration of oligomers into foodstuff}

A specific migration limit (SML) of $15 \mathrm{mg} / \mathrm{kg}$ of food is specified for the PA 6 monomer (caprolactam) in Regulation (EU) No. 10/2011. According the BfR document about PA oligomers (BfR, 2019) a group migration value of $5 \mathrm{mg} / \mathrm{kg}$ of food is considered toxicologically acceptable
The sum of oligomers in the three food studied was below the established limit of $5 \mathrm{mg} / \mathrm{kg}$ (figure 2). Simulants established for beans are ethanol $10 \%$ and sunflower oil. In this case, the sum of oligomers migrated to ethanol $10 \%$ was $7 \mathrm{mg} / \mathrm{kg}$, overestimated migration, the migrated oligomers into sunflower oil was $1.4 \mathrm{mg} / \mathrm{kg}$, which underestimated the migration values since the sum of the oligomer migration to beans was $2.8 \mathrm{mg} / \mathrm{kg}$. In this case, the spatula didn't comply with the SML when working with the simulants. Nevertheless, it complied when real food was tested. Migration of PA 66 monomer was lower in beans than in ethanol $10 \%$. The migration of the PA 6 monomer was lower than the migration found in sunflower oil. It could be due to the amount of fat in this food (8.3\%).

Tabla 1. Compounds detected by UPLC-IM-Q/TOF, retention time, measured $\mathrm{m} / \mathrm{z}$, elemental composition and CCS detected

\begin{tabular}{|l|l|l|l|l|}
\hline Compounds & $\begin{array}{l}\text { RT } \\
(\mathrm{min})\end{array}$ & $\mathrm{m} / \mathrm{z}$ & Formula & $\begin{array}{l}\text { CCS } \\
\left(\AA^{2}\right)\end{array}$ \\
\hline PA 6 monomer & 2.50 & 113.0841 & C6H12N0 & 127.88 \\
\hline PA 6 dimer & 2.29 & 227.1753 & C12H23N2O2 & 155.44 \\
\hline PA 6 trimer & 3.10 & 340.2593 & C18H34N3O3 & 182.05 \\
\hline PA 6 tetramer & 3.66 & 453.3436 & C24H45N4O4 & 209.73 \\
\hline PA 6 pentamer & 4.03 & 566.4269 & C30H56N5O5 & 237.61 \\
\hline PA 6 hexamer & 4.33 & 701.4928 & C36H66N6O6Na & 265.41 \\
\hline PA 66 monomer & 2.61 & 227.1753 & C12H23N2O2 & 153.61 \\
\hline PA 66 dimer & 3.88 & 453.3437 & C24H45N4O4 & 214.07 \\
\hline PA 66 trimer & 4.55 & 701.4935 & C36H66N6O6Na & 270.69 \\
\hline
\end{tabular}


Simulants established for chicken soup were ethanol $10 \%$, acetic acid $3 \%$ and sunflower oil (with a correction of value/3). In this case, ethanol $10 \%$ and acetic acid 3\% overestimated migration (sum of oligomers was 7 and $7.8 \mathrm{mg} / \mathrm{kg}$ ), and they didn't comply with the SML. Sunflower oil underestimated migration $(1.4 \mathrm{mg} / \mathrm{kg})$ when it is compared with real values of soup migration $(4.3 \mathrm{mg} / \mathrm{kg})$. Migration of caprolactam to soup $(0.15 \mathrm{mg} / \mathrm{kg})$ was below migration of this monomer to sunflower oil (3.2 $\mathrm{mg} / \mathrm{kg}$ ). It could be due to the amount of fat in this food (0.3\%). Moreover, the value of migration of caprolactam was below the migration found in beans that had a higher amount of fat. It suggested that fat content would be the factor that affects caprolactam migration.

Finally, whole milk was studied: Simulant for whole milk was ethanol 50\%. This simulant overestimated the migration $(9.8 \mathrm{mg} / \mathrm{kg})$ when it was compared to the migration to whole milk, whose migration value was $3.3 \mathrm{mg} / \mathrm{kg}$ (value below SML).

\section{Conclusions}

UPLC-IMS-Q-TOF has been the required analytical technique for the identification of oligomers in migration extracts since it allowed to identify oligomers with the same elemental composition, the same CCS value but different fragmentation pattern. Migration of the identified compounds was done and it was observed that migration of PA6 and PA 66 oligomers to ethanol $95 \%$, that is commonly used as substitute of sunflower oil overestimated the migration when compared with migration to sunflower.

\section{References}

[1]. Abe, Y., Mutsuga, M., Ohno, H., Kawamura, Y., Akiyama, $\mathrm{H}$. Isolation and Quantification of Polyamide Cyclic Oligomers in Kitchen Utensils and Their Migration into Various Food Simulants. Plos One, 2016, 11(7). 1-15. Avaliable from: doi:10.1371/journal.pone.0159547.

[2]. BfR, 2019. Polyamide Kitchen Utensils: Keep contact with hot food as brief as possible.

[3]. Kappenstein, O., Ebner, I., Forster, C., Richter, S., Weyer, J., Pfaff, K., Luch, A. Validation and application of an LCMS/MS method for the determination of cyclic oligomers originating from polyamide 6 and polyamide 66 in food simulant. Food Additives and Contaminants Part A, 2018, 35, 1410-1420. Avaliable from: doi: 10.1080/19440049.2018.1448944

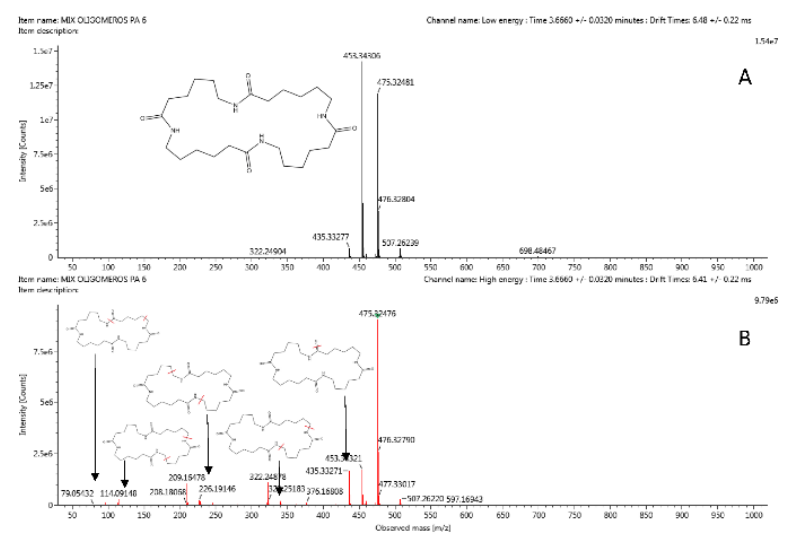

Figure 1. A) Low energy spectrum of the PA 6 tetramer obtained by UPLC-IMS-Q-TOF for the food simulant ethanol 95\% B) high energy spectrum of the PA 6 tetramer obtained by UPLC-IMS-Q-TOF for the food simulant ethanol 95\%

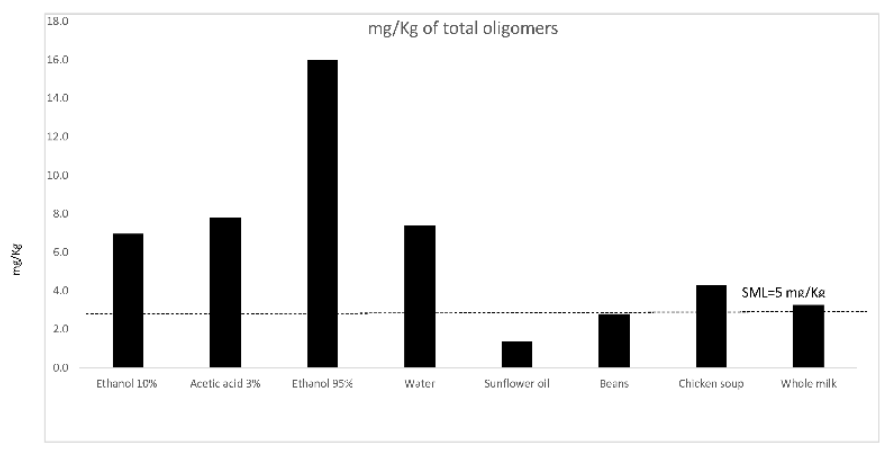

Figure 2. Migration (mg/kg) of the sum of oligomers for each simulant or food studied

Revista “Jornada de Jóvenes Investigadores del I3A”, vol. 8 (Actas de la IX Jornada de Jóvenes Investigadores del I3A -11 de diciembre de 2020). ISSN 2341-4790. 